\title{
EL VUELO MÁGICO POR LOS ANDES EN EL BERNARDO DE BERNARDO DE BALBUENA ENTRE DOS FUNCIONALIDADES
}

\author{
POR \\ Roger FriedLein \\ Ruhr-Universität Bochum
}

LAS REPRESENTACIONES DEL ESPACIO ANDINO EN LA POESÍA COLONIAL DE LA EDAD MODERNA

Como se suele afirmar y no deja de ser correcto, el paisaje en la poesía o la literatura en general -entendido como la representación de un escenario abierto y concreto, percibido por la conciencia de un sujeto- es un invento del Romanticismo y de su estética individualista. Los románticos utilizan representaciones de paisajes, preferentemente autóctonos, para la sublimación del yo y la consiguiente construcción identitaria individual y colectiva. En cambio, la estética anterior al Romanticismo, marcada por la imitación y superación de textos modélicos y otros fenómenos de la intertextualidad, ofrece menos ocasiones para el despliegue de espacios paisajísticos y, por tanto, individualizados. Sin embargo, el espacio natural y su descripción no están ausentes de la poesía antigua, y ni siquiera faltan en ella los espacios identificados con nombres concretos y reales, y cuya descripción ocupa pasajes considerables de los textos en cuestión. La diferencia reside en que en vez del espacio percibido paisajísticamente, se encuentran descripciones geográficas. Un lugar predilecto para esa materia es la poesía épica que posee una densa tradición de descripción geográfica, estable a través de las épocas, y cuyo análisis ha merecido relativamente poca atención.

\section{EPISODIOS COSMOGRÁFICOS EN LA POESÍA ÉPICA}

Las descripciones geográficas están presentes desde el principio en la recuperación del poema épico de cuño antiguo en el Renacimiento, y permanecen hasta en sus más recientes representantes en el siglo XX. En los reinos de las coronas de Castilla y de Aragón, los primeros poemas épicos según los modelos antiguos surgen a partir de los años 1550 , y son textos casi siempre vinculados con las cortes de reyes, virreyes, nobles y prelados eclesiásticos que se ocupan en su mayoría de los dos temas militares dominantes del momento: los conflictos bélicos mediterráneos, sobre todo con el Imperio 
otomano, y la expansión al Nuevo Mundo. Cualquier otro tema -caso aparte la épica religiosa- forma una excepción: la epopeya renacentista se presenta pues como una forma antigua que retoma los modelos de Virgilio, Lucano y Homero, aplicándolos a las materias de la actualidad. Desde su principio esa renovada tradición épica incorpora las descripciones geográficas panorámicas, un tipo de episodio tan o más frecuente que otros ingredientes épicos como los motivos de la batalla naval, la profecía dinástica, la cueva mágica que contiene una galería de artefactos, o el concilio de los dioses.

Como esos motivos, también el panorama geográfico se encuentra in nuce en Virgilio y Homero; sin embargo, su modelo más decisivo no proviene de la épica: el famoso Somnium Scipionis era originalmente un pasaje de un diálogo de Cicerón y fue posteriormente leído como texto independiente. En este relato onírico, el alma de Escipión se eleva por las esferas encima de la tierra y contempla sus regiones. Las epopeyas renacentistas suelen integrar ese tipo de panorámica geográfica-la mayoría de las veces percibida desde un vuelo en una carroza mágica, pero otras veces también sin ella-, asignándole funciones diferentes.

Una de las primeras epopeyas de la corte de los Austrias, el Carlo famoso de Luis Zapata, podría haber conformado el ejemplo más temprano en el espacio hispánico, ya que su autor anuncia en varios lugares del poema la insertación de una serie de episodios geográficos en unos rótulos como por ejemplo "Aquí va el viaje de Torralba" que en la editio princeps no fueron retirados de en medio del texto, ni tampoco substituidos por los episodios que anuncian, los cuales según parece nunca llegaron a ser escritos.

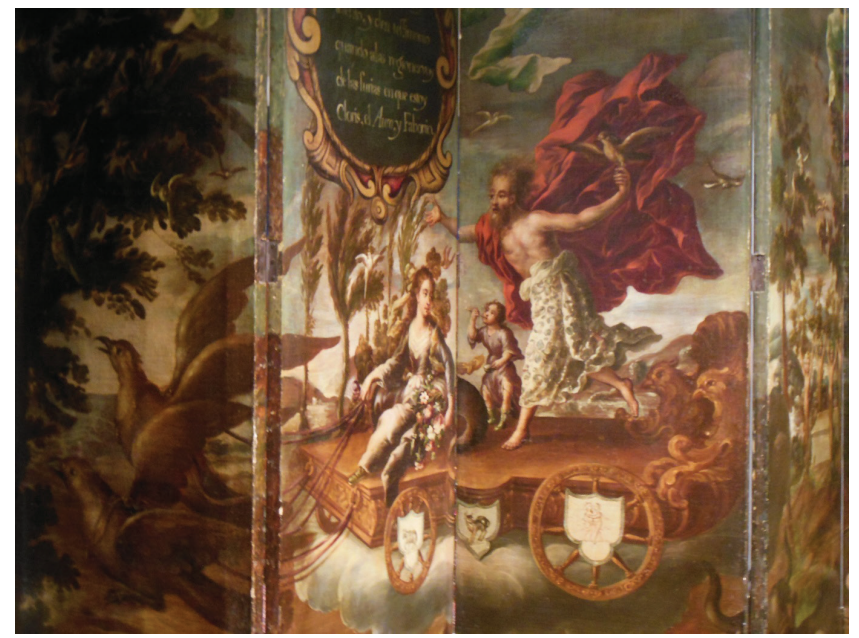

Biombo en el Museo Franz Mayer de México D.F., que representa una carroza volante.

Revista Iberoamericana, Vol. LXXXI, Núm. 253, Octubre-Diciembre 2015, 1077-1094 
Merecidamente más famoso en la filología hispánica es el panorama mundial que forma parte del episodio de La Araucana de Alonso de Ercilla y Zúñiga en el que el protagonista y narrador del poema penetra al jardín del mago Fitón. El mago le permite la contemplación del mundo y sus regiones en su bola de cristal. Pocos años antes de la publicación de ese episodio, Luís de Camões había editado en Lisboa sus Lusíadas, poema épico en cuyo episodio más conocido los marineros protagonistas acaban su viaje de regreso de la India en una isla mitológica donde tienen ocasión de ver la máquina mundi con sus esferas y los países y regiones del futuro imperio lusitano en el centro de él.

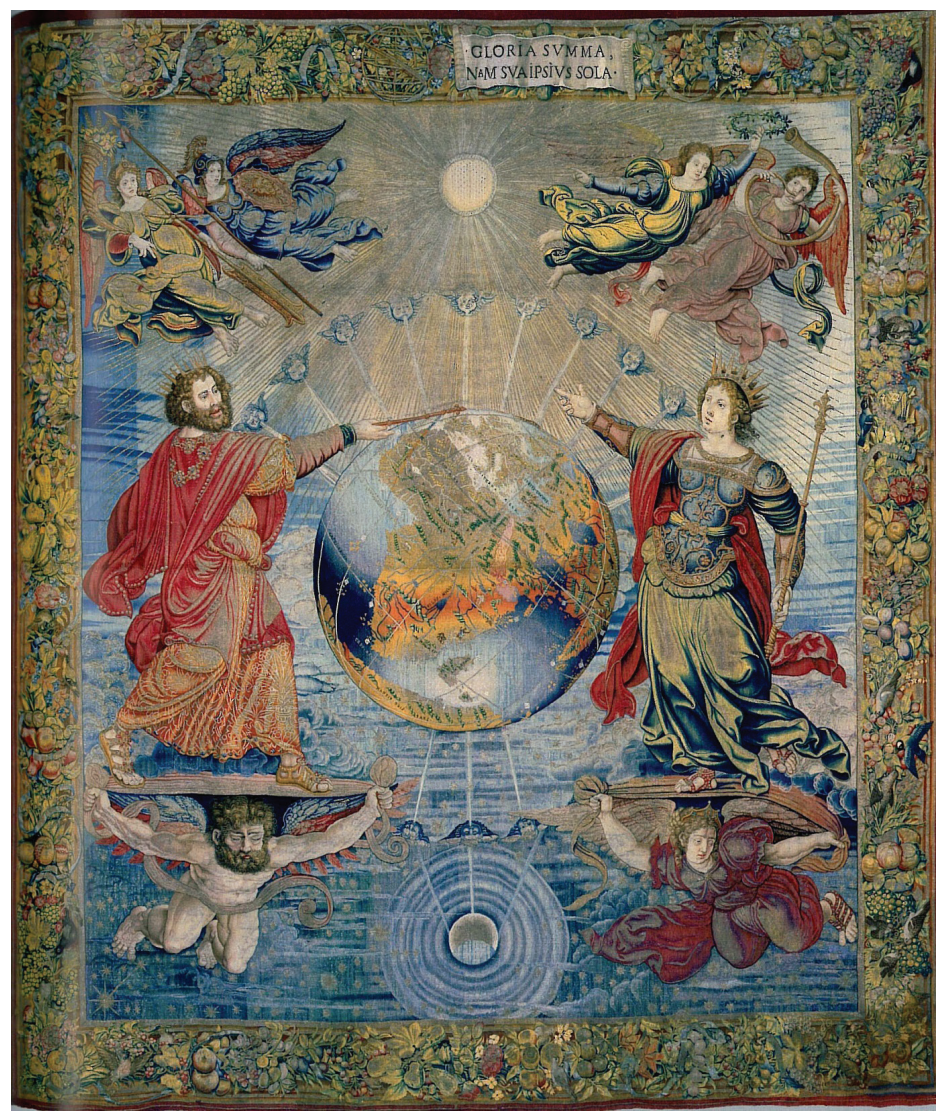

Tapiz encargado por la familia real portuguesa en el que se muestra una escena parecida a la cosmovisión en Os Lusíadas.

Revista Iberoamericana, Vol. LXXXI, Núm. 253, Octubre-Diciembre 2015, $1077-1094$
ISSN 2154-4794 (Electrónico) 
Alonso de Ercilla entrará con La Araucana en el juego de imitación y superación del modelo camoniano, siendo éste un ejemplo representativo de esa dinámica que tanto caracteriza la literatura renacentista (ver Nicolopulos).

Al lado de las epopeyas históricas, también la segunda línea de tradición épica en el mundo hispánico no se priva de ese tipo de episodios. Desde el mismo momento de mediados del siglo XVI en que empieza a haber epopeyas históricas españolas, existen también los poemas que desarrollan el modelo del romanzo italiano y su representante más conocido, el Orlando furioso, y también ellos incorporan episodios geográficos. Estos poemas épicos caballerescos suelen ser ambientados en un mundo vagamente medieval y claramente ficticio. Los autores de los reinos hispánicos, políticamente enfrentados con Francia en aquel momento, modifican la ideología política de esas adaptaciones del modelo italiano sustituyendo a Orlando/Roldán y sus compañeros como héroes por un homólogo hispano, Bernardo del Carpio. Sin ser el único ejemplo de esa línea de epopeya italianizante, El Bernardo de Bernardo de Balbuena, junto con los poemas caballerescos de Luis Barahona de Soto y de Lope de Vega, forma el texto más conocido de esa línea (Pierce, La poesía épica; Chevalier, L'Arioste).

Frecuente en ambos ramos de la tradición épica renacentista, histórica y caballeresca, el panorama geográfico incluye en el ejemplo balbueniano una visión de la cordillera andina. Con ello se inicia una serie de panoramas andinos a la que contribuyen poemas épicos americanos del siglo XIX -como es el caso del brasileño Sousândrade en $O$ Guesa-e incluso el siglo XX, como lo comprueba el famoso ejemplo de Pablo Neruda en su Canto general.

\section{Bernardo de Balbuena: El Bernardo}

Bernardo de Balbuena nació en 1561 en Valdepeñas en La Mancha castellana, pero vivió desde 1585 con excepción de unos pocos años en México y el Caribe; abad en la isla de Jamaica desde 1610 y posteriormente obispo en Puerto Rico, murió en 1627 en esa isla. Conocido hoy sobretodo por su poema de elogio de la Ciudad de México, $L a$ Grandeza mexicana (1604), y por su novela pastoril Siglo de oro en las selvas de Erifile (1608), Balbuena tiene su tercer y mayor texto con El Bernardo, editado póstumamente en 1624 (Rojas Garcidueñas, Bernardo). Cuando se le ve al autor hoy día editado como poeta lírico se trata, salvo unos pocos poemas ocasionales, de pasajes extraídos de los textos mencionados. Además de ellos podría haber existido una Cosmografía de su pluma que nos es conocida únicamente a través de una referencia en un poema.

Sin duda, El Bernardo se encuentra a la sombra de La Grandeza mexicana y de la Erifile en la recepción contemporánea porque un texto como La Grandeza mexicana se presta más para la construcción de una historia literaria mexicana o latinoamericana que la epopeya bernardiana, ambientada en su casi totalidad en Europa. Además, se hace perceptible que en el año de edición de 1624, El Bernardo como poema épico

Revista Iberoamericana, Vol. LXXXI, Núm. 253, Octubre-Diciembre 2015, 1077-1094 
caballeresco llega de cierto modo tarde. Varios indicios apuntan a que fuese redactado ya desde los años 1580, mientras el prólogo podría ser del año 1615. La situación editorial del texto no ha mejorado en gran medida desde su edición en el volumen de poemas épicos que Cayetano Rosell compiló para la Biblioteca de Autores Españoles en 1851/1854; posteriormente, un intento norteamericano de edición crítica se quedó por su parte inédito, y fue seguido sólo por una reimpresión mexicana de la edición de Cayetano Rosell.

Al contrario de las epopeyas históricas, en las que un vuelo panorámico realizado por arte de magia como el que se encuentra en El Bernardo sería difícil de justificar, un poema del cariz de El Bernardo, de tradición italiana, no plantea ningún problema de justificación para la integración de ese tipo de elementos mágicos, ya que la programática poética postula no la "verdad" de los hechos sino su "verosimilitud" como valor estético dominante, lo cual no excluye los elementos que causan la "maravilla" en el lector. Magos, hadas y sus maravillas, como los vuelos panorámicos y los encantos mágicos, integran el arsenal poético de esos textos. En seguida se tratará de analizar las características ideológicas y funciones semánticas de un episodio que es uno de los ejemplos más significativos de lo maravilloso en El Bernardo (Chevalier, "Sur les éléments"; Rodilla León).

\section{Características de El Bernardo}

El contexto narrativo del vuelo mágico en El Bernardo está formado por el complicado entramado de episodios típico del género épico caballeresco. Sigue siendo útil el estudio de John Van Horne que se enfrenta con la tarea de desentrañar el conglomerado de la acción de cada uno de los personajes, ofreciendo además resúmenes de los cantos con sus paralelos más significativos en la épica antigua. En general, la acción de El Bernardo está organizada en cuatro hilos narrativos en orden no cronológico. El hilo central acompaña la vida de Bernardo del Carpio: el joven y noble Bernardo, huérfano, es educado por el mago Orontes. Un grupo de hadas, airadas contra la soberbia de Carlomagno y sus doce pares reconocen en el joven Bernardo su futuro vengador. A partir de aquí, su aventura le lleva a Oriente, le permite ganar las armas de Aquiles y le conduce por caminos tortuosos con sus viajes por la región mediterránea, su amor por la seductora Arcangélica y sus combates fantásticos, hasta la participación del héroe en la batalla de Roncesvalles contra las huestes francesas de Carlomagno, lideradas por Orlando/Roldán, cuya totalidad encuentra la muerte por la acción del caballero leonés al servicio del rey Alfonso. Un segundo hilo narrativo acompaña los hechos en la corte francesa de Carlomagno y su consejero, el mago Malgesí, a su vez enfrentado con Orontes, el sabio educador de Bernardo. Otros dos hilos narrativos siguen las aventuras de Orlando y del moro aragonés Ferragut respectivamente. Como es típico de las epopeyas caballerescas, los cuatro hilos son

Revista Iberoamericana, Vol. LXXXI, Núm. 253, Octubre-Diciembre 2015, 1077-1094 ISSN 0034-9631 (Impreso) 
orquestrados por un narrador heterodiegético que aprovecha los cambios de hilo para insertar comentarios a veces autorreflexivos en su poema. El poema balbueniano alcanza en sus 24 libros un total de unos 40.000 versos e iguala a su modelo ariostesco en volumen y complejidad narrativa.

El interés que la investigación le dedica al poema de Balbuena se ha centrado en primer lugar en su clasificación epocal en el triángulo de Renacimiento, manierismo y barroco. Si John Van Horne veía en él un poema renacentista, Frank Pierce ("El Bernardo") lo ubica en el barroco basándose en consideraciones estilísticas, mientras Alfredo Ángel Roggiano y José Pascual Buxó lo colocan dentro del manierismo. Otros temas discutidos son la ubicación del poema y su autor entre la tradición antigua, medieval y renacentista de la metrópolis europea y el criollismo del Virreinato (Barrera; Sabat-Rivers; Dolle).

En general, el poema está marcado por un fuerte "nacionalismo" español y un claro ímpetu antifrancés. Este dualismo llega al extremo de incluir en el bando hispánicoantifrancés también a los moros de la península -situación inédita en el género épico en el que los musulmanes en la Península ibérica, el Norte de Africa, el Mediterráneo o en la India Oriental figuran generalmente como los enemigos jurados de la cristiandad. El lado hispánico es liderado por Bernardo del Carpio bajo su rey Alfonso I, y el lado francés por Orlando y su rey Carlomagno. Vale la pena recordar que, en función de la situación política del siglo XVI, Carlomagno suele encarnar en los poemas del ciclo épico hispano-bernardino un personaje si no francamente negativo, por lo menos bajo influencias negativas de sus paladines pecaminosos. Existen dos contribuciones de Gilberto Triviños ("Bernardo"; "Nacionalismo") que explican esta estructura ideológica del poema de Balbuena y los valores que se asocian con cada campo. Aunque el camino de su vida lleva a Bernardo al éxito militar, el narrador explicita que desde los tiempos de Carlomagno en que se produjo, ese éxito no fue nunca dignamente consignado por la poesía y, por lo tanto, permaneció desconocido para la posteridad. Hubo que esperar la llegada de un poeta homónimo del siglo XVI, Bernardo de Balbuena, y el hallazgo de un viejo manuscrito con las gestas de Bernardo del Carpio para unir las armas de éste con las letras de aquél: sólo en colaboración de los dos Bernardos y mediante el poema balbueniano se podrá, finalmente y con un atraso de varios siglos, realizar la fama del héroe leonés. Esta original construcción autorreflexiva entre el protagonista y el autor se realiza en una serie de episodios de los que el vuelo por los Andes forma parte, como veremos en seguida.

\section{LA CONSTRUCCIÓN AUTORREFLEXIVA EN EL BERNARDO}

Concretamente, el complejo autorreflexivo consta de cuatro partes, repartidas entre los libros XV y XVII del poema. La primera empieza después de un naufragio en aguas griegas, cuando Bernardo se salva en una playa de la costa del golfo de Corinto

Revista Iberoamericana, Vol. LXXXI, Núm. 253, Octubre-Diciembre 2015, 1077-1094 
a las faldas del monte Parnaso. Aún exhausto del accidente naval, se duerme en una cueva, y en su sueño, que le lleva más adentro del maravilloso lugar, se encuentra en una bifurcación de su camino -igual que el mitológico Hércules in bivio (Enenkel; Sansone)-que implica una decisión moral; Bernardo, decidiéndose por la virtud, recibe una centella de la diosa Temis en su frente, y a partir de aquí estará capacitado para conquistar la fama. Esa conquista se materializa en la continuación del sueño en la que el soñador Bernardo conquista el monte Parnaso, eliminando a golpe de espada a los malformados personajes que en la cueva de Temis se habían dejado arrastrar por la corriente materialista del pecado. Bernardo, en cambio, subirá al monte Parnaso para obtener de manos de Apolo una plaza reservada para él en el Templo de la Inmortalidad. Antes de relatar esta segunda parte triunfal del sueño de su protagonista, el narrador inserta el relato de un segundo sueño, que es ahora soñado por el propio narrador: en el momento de redactar el sueño de Bernardo, una figura femenina se habría llevado al narrador en una carroza volante, movida por grifos, en un viaje aéreo maravilloso (ver los trabajos de Triviños). La diosa que dirige la carroza, quejándose del mal estado moral del mundo, habría ofrecido su ayuda al narrador para mejorar su escritura:
Y porque en feliz curso la jornada
De tu española monarquía acabes,
Y tu heróica grandeza comenzada
De historias llenas y sentencias graves,
Conmigo vén; que estoy determinada
Al vuelo de mi carro y de sus aves
Mostrarte, para luz de tu escritura,
Clara una senda, en estos dias oscura.
(Bernardo XV, estr. 10)

Como Triptolemo, el fundador mitológico de la agricultura en Grecia, el narrador soñador sobrevuela el mundo y contempla mares y tierras. Sin embargo, su visión panorámica no despliega el detallismo topográfico que este motivo ostenta habitualmente, sino que se limita a la indicación sumaria de que el narrador sobrevuela la esfera de tierra y mar:

Vi el cielo, vi la tierra, vi el profundo
Mar con puntas y playas diferentes,
Y entre el primero golfo y el segundo
Montes, selvas, ciudades, rios y fuentes.
(Bernardo XV, estr. 12)

En cambio, el narrador soñante, no distraído por la contemplación geográfica, sí se ocupa de dejar caer "perlas ó flores" desde la carroza al suelo, algunas de las

Revista Iberoamericana, Vo1. LXXXI, Núm. 253, Octubre-Diciembre 2015, 1077-1094 
cuales serán recogidas intactas por los espectadores del vuelo, otras caerán al suelo desaprovechadas. La visión de la tierra desde el vuelo no proporciona al pasajero de la carroza un saber de erudición geográfica, pero sí aumenta su discreción humana, una capacidad de entendimiento sistemático y ético, que le posibilita al narrador el dar y repartir entre el público sus "perlas" (en clave metapoética: sentencias) o "flores"(frutos de lectura) -un vuelo marcado por la generosidad ético-moral de un yo deleitado por su acción, en vez del ávido chupar sensual y deleitoso que pratican los compañeros de otro viaje que será escenificado después:

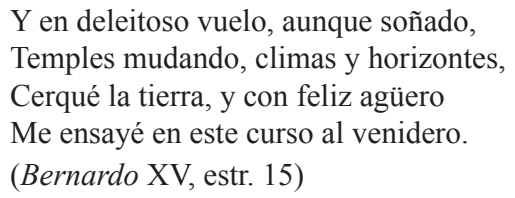

El "curso venidero" aquí mencionado formará la tercera parte del complejo autorreflexivo. Hasta aquí los "dos Bernardos", el protagonista y el narrador, reciben pues en sus respectivos sueños una espécie de consagración. El caballero para sus actos de fortitudo, y el narrador para sus actos de escritura que sembrarán simientes morales en su público. Será entre los dos que constituirán la fama de Bernardo del Carpio, estableciendo de esta manera una relación tipológica en el sentido de la exégesis bíblica como lo había definido Friedrich Ohly ("Typologie"): Bernardo de Balbuena cumple la profecía in factis realizada por Bernardo del Carpio y la completa en un texto que reune armas y letras hispánicas.

En ese contexto metapoético se encuentra emplazado el episodio del viaje aéreo de Malgesí, el mago francés, que ejerce el mando del viaje intercontinental. La figura de ese mago procede de la matière de France de los cantares de gesta medievales, situada alrededor de Carlomagno y su corte, y que fue integrada a la épica orlandesca en Italia y, con las adaptaciones ideológicas mencionadas, a la bernardina en España. El personaje de Malgesí ya sale en algunas epopeyas caballerescas hispánicas anteriores a Balbuena, como en los poemas de Nicolás Espinosa, Francisco Garrido de Villena y Martín de Bolea y Castro, sin embargo, sin llegar a recibir en ellos la misma carga metapoética que le da Balbuena en El Bernardo.

\section{El vuelo máGico de Malgesí}

El Malgesí de Bernardo de Balbuena es un nigromántico que conjura a los espíritus del infierno para que su nave alce el vuelo. De moralidad aún más dudosa que él, los otros tres pasajeros presentan claramente marcas de vicios, además de pertenecer al bando francés, condenado por la totalidad del poema. La tripulación del vuelo consta

Revista Iberoamericana, Vol. LXXXI, Núm. 253, Octubre-Diciembre 2015, 1077-1094 
pues del nigromante Malgesí, el gigante Morgante (superbia), el pagano rei de los persas Orimante (luxuria) y el caballero francés Reinaldos. ${ }^{1}$ Malgesí promete mostrarles lo que un día -visto desde la poco concreta Edad Media en la que se ambienta la acciónserá llamado el Nuevo Mundo; sin embargo, se acatará primero el deseo de Morgante y el viaje pasará por encima de Europa, donde los pasajeros contemplarán las tierras de Grecia, Italia, Francia, y finalmente, muy por extenso, las regiones de España y sus grandezas, siguiendo de esa manera el orden histórico de una versión hispánica de la translatio imperii (Bernardo XV, estr. 146 - XVI, estr. 207). Después de esa primera parte del viaje, la nave se eleva hasta la altura de la luna y los pasajeros contemplan los astros y las constelaciones (Bernardo XVI, estr. 208 - XVII, estr. 33 y XVIII, estr. 94-100). Pero Malgesí no ignora el peligro que emana del mundo fantástico de la luna y dirige la nave de nuevo hacia abajo, para que en la tercera y última parte del viaje los pasajeros vean el Nuevo Mundo, empezando en su punta Sur y continuando hacia el Norte hasta que un mago de nombre Tlascalán les obliga a aterrizar en su cueva. Debido sobretodo a la parte dedicada a la Península ibérica, la extensión del episodio cosmográfico en El Bernardo supera con creces sus antecedentes en Os Lusíadas o La Araucana. Del mismo modo la descripción del equipamiento mágico en la cueva y taller de Tlascalán supera los pasajes correspondientes relativos a la cueva de Fitón en La Araucana. La tercera parte del viaje por la cordillera andina siempre ha atraído el máximo interés de los lectores modernos de la epopeya balbueniana, formando la base argumentativa para la tesis del criollismo de su autor, vista la relativa riqueza de la descripción de las tierras americanas:

Ven hácia el sur tendidas las regiones
Y el belicoso clima de la tierra,
Que en los ménos altivos corazones
Discordia influye, presuncion y guerra;
Hasta los encubiertos Patagones
Y el largo trecho que sus playas cierra,
Por donde Magallanes, sin contienda,
Del rico oriente halló la inútil senda.
Ven del Brasil los páramos incultos,
Los Andes, el Dorado y los temidos
Desiertos del Dayren, llenos de insultos,
Aunque frescos entónces y floridos:
Del viejo y mozo Potosí los bultos,
De riquezas preñados y hoy paridos,
Y las playas de Chile de oro llenas,

1 En francés, Renaud (de Montauban); en italiano, Rinaldo.

Revista Iberoamericana, Vol. LXXXI, Núm. 253, Octubre-Diciembre 2015, 1077-1094 ISSN 0034-9631 (Impreso) 
Y ahora mas de sangre que de arena.

La rica tierra y blancos arenales

En que llover no supo el seco cielo,

Y la vecina sierra y sus raudales,

Que en frescos valles dan partido el suelo:

El Cuzco, de los Ingas naturales

Silla imperial, y el claro y fértil vuelo

Con que la equinoccial, sembrando brasa,

Por los muros de Quito rompe y pasa.

En Panamá y su costa el nudo estrecho

Que dos contrarios mundos encadena.

Y el hueco monte que, de llamas hecho,

De Nicaragua por las playas suena:

Del Valle de Campeche el dulce pecho

Queda de roja miel y abejas llena,

Y los verjeles que el cacao señala

Por el rico Tabasco y Guatemala.

(Bernardo XVIII, estr. 103-106)

El vuelo por la cordillera americana sigue el modelo de los episodios cosmográficos en Camões y Ercilla en su estructura básica, que consiste en una enumeración de las regiones contempladas en la que de cada una de ellas se hace mención de un elemento principal que la caracteriza. Mientras que en la parte europea del viaje, Malgesí comenta y explica los parajes contemplados a sus compañeros, en la parte americana las informaciones son dadas por la voz del narrador que habla desde su propio presente (hoy, ahora) y se refieren en su mayoría a la orografía y naturaleza del espacio sobrevolado en el que los grandes nucleos urbanos Cusco, Potosí y Quito están integrados, sin que las características debidas propiamente a la acción de los habitantes de estas ciudades adquieran especial destaque, ya que el viaje se realiza en un momento de la época prehispánica. Cuando la compañía de viaje se encuentra encima de México y del volcán de nombre Jala, ${ }^{2}$ el mago indio Tlascalán, identificado después explícitamente como tlaxcalteca, obliga a los viajeros al aterrizaje en su suntuosa cueva. Por la boca del mago, los pasajeros del vuelo naufragado escucharán una profecía sobre la conquista del Nuevo Mundo por los españoles y presenciarán un cataclismo en el que las paredes de la riquísima cueva se derriban, la cueva se hunde y los pasajeros de la nave sólo consiguen salvarse volviendo al Viejo Mundo por un túnel debajo del Atlántico [(Bernardo XVIII, estr. 101-112 (vuelo por el Nuevo Mundo), estr. 113-182 (cueva de Tlascalán) y Ber XIX, estr. 1-93 (profecía de Tlascalán y hundimiento de la cueva)].

2 El nombre actual del volcán es El Ceboruco, situado cerca de la ciudad de Jala en el estado de Nayarit.

Revista Iberoamericana, Vol. LXXXI, Núm. 253, Octubre-Diciembre 2015, 1077-1094 
En primer lugar, destaca en el texto de Balbuena el hecho de que el vuelo del cuarteto caballeresco está marcado por el deleite que los pasajeros sienten al volar (gozar, gusto, deleite) y por la majestad y hermosura de la panorámica -ésa se hace notar sobre todo en los pasajes ibéricos del viaje:
Y ellos, siguiendo el celestial camino,
Del asombrado mundo van gozando,
Cuando el suelo de léjos ven latino
La hermosura del mundo sustentando.
(Bernardo XVI, estr. 7)

Tanto es que Orimandro -emperador oriental, se le presenta con una acusada tendencia hacia las delicias sensuales- le ruega a Malgesí expresamente por razones de placer (deleite) de proseguir con el vuelo y con su discurso descriptivo de lo visto. La inclinación por el deleite de la contemplación concuerda con el carácter de Orimandro sujeto a las pasiones que tanto se manifiestan en su amor ciego por la princesa Angélica como en el deleite experimentado en las "grandezas de España":
Y pues que vos, por sabio y por vecino,
Podeis darnos razon y luz de todo,
Gobernad el timon y abrid camino
Por este aire benévolo, de modo
Que yo os deba este gusto á que me inclino,
$\mathrm{Y}$ el contar su grandeza al reino godo,
Y todos tres gozar en este vuelo
La majestad de tan heróico suelo.
Dijo; y el frances mágico, ahora sea
Por dar al persa gusto y á Morgante,
Que lo mismo parece que desea
En los halagos del feroz semblante;
O por curiosidad, en que se vea
De su leccion y ciencia lo importante;
Que es gusto al fin mostrarse un hombre sabio,
Y entre reyes mover á tiempo el labio [...]
(Bernardo XVI, estr. 49-50, énfasis mío)

Cuando la carroza se aproxima a la luna, los viajantes están tan entregados al placer de su viaje que pierden el sentido de la dirección:

Absortos al placer de andar volando

En medio de ambos climas, ya sin tino,

Revista Iberoamericana, Vol. LXXXI, Núm. 253, Octubre-Diciembre 2015, 1077-1094 
Ni ven si van subiendo ó si bajando, Ni de cuál mundo siguen el camino (Bernardo XVIII, estr. 100, énfasis mío)

La luna, mudable como la fortuna en su crecimiento y diminuición continuas, se asocia con el vicio en el poema de Balbuena y remite a la luna del Orlando Furioso, un contramundo en el que los viajantes podrían perder el juicio.

Como sus compañeros de viaje, también el mismo Malgesí disfruta del viaje. Su deleite, en cambio, no se origina como el del rey persa en la visión majestuosa de las regiones, sino en la ostentación de su propio saber (ciencia) mediante sus explicaciones y de su capacidad de enseñar (lección). La auto-ostentación, no exenta de soberbia, va de la mano con la curiosidad experimentada por los pasajeros (ver arriba, citación Bernardo XVI, estr. 50). Sucumben a la tentación de lo nuevo y nunca visto del mundo material, a la curiositas oculorum que trae el deleite sensual de la visión y un saber hecho de nombres, que en sí están vacíos y se despliegan en el texto por puro deleite verbal. En el discurso ortodoxo agustiniano como también aquí, un tal comportamiento no deja de ser pecado por vanidad (Blumenberg; Vincken y Krüger). En lugar de los viajes exteriores por el mundo material, el discurso de San Agustín aboga por los viajes al interior del alma para buscar su bien, una concepción mucho más conforme con el viaje soñado del narrador que con la excursión placentera de la compañía del viaje francesa. Este viaje aéreo transandino que fracasa en México, tan apreciado por los lectores modernos, es realizado por la ilustre banda de un mago francés, un gigante y un rey persa, y obedece al afán de placer y la curiositas oculorum de los viajantes pecadores.

\section{Función DEL VIAJE DE MALGESÍ EN CONTRAPOSICIÓN AL VIAJE DEL NARRADOR}

Sensiblemente diferente se había dibujado el viaje aéreo en el sueño del narrador, sin accidentes orográficos concretos, sin nombres geográficos ni vana ostentación del saber. En él se elevaba un personaje cuyo vuelo seguía la finalidad de repartir por el mundo las "perlas ó flores" de su discurso en un viaje virtuoso que le asigna al saber del mundo, no detallista, el lugar subalterno que le corresponde. Bernardo del Carpio, el personaje complementario del narrador, ni siquiera vuela alguna vez: virtuoso, se queda en el suelo, combate al vicio y obtiene el acceso al monte Parnaso. En contrapartida, parece no ser casual que los pasajeros del vuelo de Malgesí sobrevuelen Grecia e incluso el paisaje de Acaya sin ni siquiera hacer alguna mención del monte Parnaso.

Por lo tanto, el paisaje andino de El Bernardo que se vincula con la tradición de los panoramas geográficos de la poesía épica antigua, remite en primer lugar, dentro de un panorama geográfico mayor, al saber del mundo material -un saber atractivo para la percepción sensual, pero en último término inútil y vacuo-. Visto en su totalidad, el

Revista Iberoamericana, Vol. LXXXI, Núm. 253, Octubre-Diciembre 2015, 1077-1094 
complejo metapoético de El Bernardo actualiza en primera instancia un discurso que en el contexto discursivo de principios del siglo XVII resulta ser ya de rancia ortodoxia contrarreformista. Sin embargo, después de la identificación del discurso de base, hay que tomar en cuenta otros elementos y dimensiones del texto y su contexto.

Visto ese último, el discurso de la curiositas augustiniana parece difícilmente sostenible en el marco de la realidad náutica y económica de los siglos XVI y XVII en el Nuevo Mundo, donde esta postura ortodoxa condenaría el interés por el marco natural y geográfico en el que tanto el narrador como el propio autor se encuentran y de cuyo conocimiento dependen sus actividades económicas y también religiosas. En parte fue en función de estas nuevas realidades que en el momento en que Balbuena redacta su poema, la curiositas ya había sido revalorada positivamente en muchos de los textos surgidos a lo largo de los descubrimientos, de manera que una postura ortodoxamente augustiniana resultaría ya excéntrica. También llama la atención que dentro del conjunto de las obras balbuenianas, un poema como la Grandeza mexicana con su minuciosa descripción elogiosa de la Ciudad de México, marcadamente visual y claramente exenta de cualquier sospecha de pecado, se inscribe en un discurso diametralmente contrario a la condena de la curiositas.

Sin embargo los contraindicadores de más peso se encuentran dentro de $E l$ Bernardo mismo. El tono general del texto y en especial del viaje aéreo de Malgesí resulta ligero y alegre, y no evoca por sus rasgos estilísticos el discurso de suma seriedad de los Padres de la Iglesia o de la teología de la época. El mago Malgesí, a pesar de sus veleidades de sabio autosuficiente, no deja de ser una figura simpática. Su magia negra no parece arrojar grandes sombras sobre su personalidad. Lo que ya se ha demostrado para Fitón en La Araucana y para otros magos en los libros de caballerías (Gómez-Montero) no deja de ser cierto para él, así como para el segundo mago del episodio, Tlascalán: la nigromancia de los magos, neutralizada o incluso banalizada, no se problematiza como tal, sino que suele ser imagen para otros conceptos como el saber y, además, en el caso de Malgesí, su ostentación y, en el caso de Tlascalán, su condición de perecedero. Repetidamente, Malgesí es llamado “sabio" sin restricciones perceptibles. Forma parte de su habildad de piloto de la nave aérea el saber contornar los peligros del reino engañoso de la luna:

\footnotetext{
[...] Cuando el diestro piloto en curso blando

Cambió el timon, y mareando el lino,

Las bolinas trocó, y humilló el vuelo;

Que es de riesgo sin fe subirse al cielo.

(Bernardo XVIII, estr. 98)
}

Aunque en este pasaje se recuerda su falta de fe, sus acciones en cambio no carecen de prudencia. Malgesí no sobrevalora la significación de lo terrenal y hace preceder sus

Revista Iberoamericana, Vol. LXXXI, Núm. 253, Octubre-Diciembre 2015, 1077-1094 
explicaciones por un discurso sobre la pequeñez del mundo material en comparación con la grandeza de Dios, y la inconstancia y corrupción de las aspiraciones y acciones humanas, sujetas al poder de Fortuna:

Mirad, dijo, en el mundo y sus regiones

Cuán breves puntos y pequeños fueros

Las grandezas alcanzan y ambiciones;

¿Qué humildes sus alcázares roqueros!

Qué abreviada parece de lo alto

La grave majestad del rey mas alto!

¡Sobre qué estrecho y breve fundamento

Estriba y pára la ambición humana!

(Bernardo XV, estr. 156)

En el fondo de estas consideraciones parece existir-siempre en el sentido positivoun desengaño de Malgesí. Perguntado por Orimandro por los antípodas y el fin del mar, Malgesí saca un telescopio (antojos) para aguzar sus sentidos, y cuando las estrellas se dejan ver, convierte su contemplación en contemplación de la grandeza de Dios que eclipsa todas las vistas terrenales anteriores:

El sabio, que en los ángulos del cielo

Tan cerca vió la celestial milicia,

De oir el son de su compuesto vuelo

Y ver sus globos de oro se acudicia;

Y ya perdiendo de la vista el suelo,

Del mundo superior dió así noticia

A aquellos que primero de la tierra

Las pobrezas contó que su orbe encierra.

¿A quién no admira tu saber profundo,

Oh Arquitecto de amor, Rey soberano [...]?

(Bernardo XVII, estr. 4-5)

La grandiosidad terrena y sobrelunar remite sólo a Dios, y la mirada al cielo eleva el espíritu hacia él:

Así por la ancha máquina del cielo

Notando el sabio iba aspectos varios,

Con prudente midiendo y fértil vuelo

Efectos uniformes y contrarios;

Mas yo, que por tan alto paralelo

Fuera voy de caminos ordinarios,

Al bajo suelo vuelvo: no suceda

Revista Iberoamericana, Vol. LXXXI, Núm. 253, Octubre-Diciembre 2015, 1077-1094 
Trastornar dos faetones una rueda.

Que en tanto que ellos por region tan nueva

Gozando van del celestial tesoro, $[\ldots]$

(Bernardo XVII, estr. 33-34)

Esta imagen positiva de Malgesí es compartida tanto por Tlascalán, que lo admira por su vuelo, como por la voz del mismo autor, que es quien habla en las alegorías en prosa, paratextuales, añadidas después del final de cada canto. De entrada hay que tener en cuenta que estas alegorías tienen carácter marcadamente puntual y casi atomista, y no ofrecen una lectura cohesionada del conjunto del poema, sino comentarios aislados. En el prólogo del autor, la validez de esas alegorías es explícitamente limitada a aquellos lectores que las buscan. Sin embargo, se puede tomar en cuenta que la alegoría del libro XIX propone una lectura del vuelo de Malgesí como significando la acción del hombre contemplativo que partiendo de las cosas materiales, alcanza las celestiales y entrevé la bienaventuranza representada por el Nuevo Mundo, pero que es desviado de ella por las preocupaciones materiales, representadas por Tlascalán y su cueva. El discurso de base de esta alegoría continua siendo el mismo que se había desprendido de la lectura de la narración, pero introduce la modificación de dividir el viaje en tres partes con valores éticos diferenciados y la figura de un capitán del vuelo positivizado, mientras sus pasajeros quedan excluidos de alegorización.

Unúltimo punto se hace valer a favor de Malgesí: el mago francés tiene antepasados españoles, pasó su adolescencia en España y recibió sus conocimientos mágicos en Toledo. Difícilmente el marco ideológico del texto con su binomio ético tajante España vs. Francia, tan claramente analizado por Gilberto Triviño, permitiría una biografía parcialmente castellana a un personaje pecaminoso. Su identidad híbrida, única en el marco del poema balbueniano con su estructura dicotómica, hace más plausible una laus Hispaniae de casi 150 estrofas de su boca, y explica la disposición positiva hacia España que se desprende, por ejemplo, de su constatación de que allí no se practica la (pecaminosa) minería:

En otras partes la codicia humana

Entra por oro á desvolver la tierra, Y en hondas grutas con sudor se afana, Y por sacarlo á luz le hace guerra: Mas aquí él solo por los riscos mana, $\mathrm{O}$ el arado al pasar lo desentierra.

(Bernardo XVI, estr. 64)

Más allá de los indicios vinculados con la persona de Malgesí hay que tomar en cuenta la dimensión del texto que se podría llamar performativa. Por más que al nivel del discurso el viaje de Malgesí sea presentado como curiosidad condenable, el mero

Revista Iberoamericana, Vol. LXXXI, Núm. 253, Octubre-Diciembre 2015, 1077-1094 
peso de las descripciones, que en su extensión superan todo lo que hasta entonces la épica española había visto, difícilmente permite una lectura de las "grandezas de España" y su prolongación providencial al Nuevo Mundo en clave negativa. La exuberancia descriptiva en la que se despliega el mundo material restringe la validez del discurso del desengaño y la pecaminosidad de manera performativa. Si ellos en última instancia hubieran de formar el mensaje del texto, no habría necesidad del fausto ecfrástico, sino que al contrario habría que suprimir sus efectos estéticos $\mathrm{y}$, en segundo término, también constituyentes de identidad; sin embargo sin ser una protoidentidad criolla, porque en este texto balbueniano, el espacio americano no es usado para aglutinar, en detrimiento de la península, a quienes lo habitan -difícilmente sería factible esta operación en el marco de un viaje que sucede en un momento cuando el espacio americano todavía no es habitado por hispánicos.

El discurso de la pecaminosidad del viaje, pues, en El Bernardo es un discurso reconocible e intencionalmente aludido, pero obediente a una finalidad argumentativa superior que relativiza la carga moral que en principio estaría implicada en él. Se funcionaliza para caracterizar al bando francés, pero no es en sí el mensaje del texto. A esa ambigüedad del citar y suspender de un discurso corresponde el personaje de Malgesí, prudente, erudito e hispanófilo, pero al mismo tiempo no exento de pecados. Más que los otros personajes como Bernardo o Roldán, que están fijados en su respectivo polo del binomio hispano-francés, Malgesí está entre las incontornables exigencias del pensamiento cristiano por un lado y la sublimación nacional por el otro. En el aludir a un discurso en función de otra finalidad argumentativa, sin actualizarlo de manera plena, se podría reconocer una de las señas epocales del manierismo tal como lo entiende Joachim Küpper.

Entre la funcionalización teórica y metapoética, por un lado, y política y constitutiva de identidades fundadas en el territorio, por el otro, los episodios cosmográficos desde el Renacimiento de Camões o Ercilla hasta la épica romántica y moderna de Sousândrade y Neruda se situan de manera individual. Habrá que continuar dándole seguimiento a la representación del espacio americano en estos episodios a través de las épocas para acompañar la formación de la identidad criolla, andina y americana.

BiBLIOGRAFÍA

Balbuena, Bernardo de. El Bernardo. Madrid: Imprenta de Gaspar y Roig. 1852. Grandeza Mexicana. Luis Íñigo-Madrigal, ed. Madrid: Biblioteca Nueva. 2012. Grandeza Mexicana. Asima F. X. Saad Maura, ed. Madrid: Cátedra. 2011. Poesía lírica. Matías Barchino, ed. Ciudad Real: Diputación. 2000. Siglo de oro en las selvas de Erifile. José Carlos González Boixo, ed. Veracruz: Universidad Veracruzana. 1989.

Revista Iberoamericana, Vol. LXXXI, Núm. 253, Octubre-Diciembre 2015, 1077-1094 
Barrera, Trinidad. "Bernardo de Balbuena, entre el Viejo y el Nuevo Mundo". Actas del XXIX congreso del Instituto Internacional de Literatura Iberoamericana. Tomo I. Joaquín Marco Revilla, ed. Barcelona: Promociones y Publicaciones Universitarias, 1994. 285-293.

Blumenberg, Hans. Der Prozeß der theoretischen Neugierde. Frankfurt: Suhrkamp,1966. Buxó, José Pascual. "Bernardo de Balbuena y el manierismo novohispano". Studi ispanici (1976): 143-164.

Chevalier, Maxime. L'Arioste en Espagne (1530-1650). Recherches sur l'influence du "Roland furieux". Bordeaux: Université de Bordeaux, 1966.

"Sur les éléments merveilleux du Bernardo de Balbuena". Etudes de philologie romane et d'histoire littéraire offertes à Jules Horrent à l'occasion de son soixantième anniversaire. D’Heur, Jean Marie y otros, ed. Tournai: Gedit, 1980. 597-601.

Dolle, Verena. “¿'Añoranza de la metrópoli” o expresión de una conciencia criolla? El Bernardo o Victoria de Roncesvalles de Bernardo de Balbuena". La formación de la cultura virreinal. Tomo II. El siglo XVII. Kohut, Karl y Sonia V. Rose, eds. Frankfurt: Vervuert, 2004. 473-503.

Enenkel, Karl. "Hercules in bivio und andere Scheidewege: Die Geschichte einer Idee bei Petrarch". Acta Conventus Neo-Latini Torontonensis. Proceedings of the Seventh International Congress of Neo-Latin Studies; Toronto 8 August to 13 August 1988. Alexander Dalzell, Charles Fantazzi y Richard J. Schoeck, eds. Binghamton: Center for Medieval and Early Renaissance Studies, 1991. 307-317. Gómez-Montero, Javier. "Phantasos in litteris. La magia ante el estatuto ficcional de 'lo maravilloso' y 'lo fantástico' de la ficción”. Brujas, demonios y fantasmas en la literatura hispánica. Jaume Pont, ed. Lleida: Universitas, 1999. 55-92.

Krüger, Reinhard. Zwischen Wunder und Wahrscheinlichkeit. Die Krise des französischen Versepos im 17. Jahrhundert. Berlin: Weidler, 2002.

Küpper, Joachim. "Die spanische Literatur des 17. Jahrhunderts und das BarockKonzept (Forschungsüberblick und Thesen)". Europäische Barock-Rezeption. Tomo I. Garber, Klaus y otros, eds. Wiesbaden: Harrassowitz, 1991.

Nicolopulos, James. The Poetics of Empire in the Indies. Prophecy and Imitation in La Araucana and Os Lusíadas. University Park: Pennsylvania State UP, 2000.

Ohly, Friedrich. "Typologie als Denkform der Geschichtsbetrachtung”. Typologie. Volker Bohn, ed. Frankfurt am Main: Suhrkamp, 1988. 22-63.

Pierce, Frank. "El Bernardo of Balbuena: A Baroque Fantasy". Hispanic Review 13/1 (1945): 1-23.

La poesía épica del Siglo de Oro. Madrid: Gredos. 1961.

Rodilla León, María José. Lo maravilloso medieval en 'El Bernardo'. Ciudad de México: Universidad Nacional Autónoma de México, 1999.

Revista Iberoamericana, Vol. LXXXI, Núm. 253, Octubre-Diciembre 2015, 1077-1094 ISSN 0034-9631 (Impreso) 
Roggiano, Alfredo Ángel. "Instalación del barroco hispánico en América: Bernardo de Balbuena". Homage to Irving A. Leonard. Essays on Hispanic Art, History and Literature. Chang Rodríguez, Raquel y Donald A. Yates, eds. Nueva York: Editorial Mensaje, 1977. 61-74.

Rojas Garcidueñas. Bernardo de Balbuena. La vida y la obra. Ciudad de México: Universidad Nacional Autónoma de México, 1958.

Sabat-Rivers, Georgina. "El Barroco de la contraconquista: Primicias de conciencia criolla en Balbuena y Domínguez Camargo". Relecturas del Barroco de Indias. Mabel, Moraña, ed. Hanover, NH: Ediciones del Norte, 1994.

Sansone, David. "Heracles at the Y". Journal of Hellenic Studies 124 (2004): 125-142. Triviños, Gilberto. "Bernardo del Carpio desencantado por Bernardo de Balbuena". Cuadernos americanos 40/3 (1981): 79-102.

"Nacionalismo y desengaño en 'El Bernardo' de Balbuena”. Acta literaria 6 (1981): 93-117.

Van Horne, John. El Bernardo of Bernardo de Balbuena: A Study of the Poem with Particular Attention to its Relations to the Epics of Boiardo and Ariosto and to its Significance in the Spanish Renaissance. Urbana: University of Illinois, 1927.

Vincken, Barbara. "Curiositas / Neugierde". Ästhetische Grundbegriffe. Historisches Wörterbuch in sieben Bänden. Tomo I. Karlheinz Barck, ed. Stuttgart: Metzler, 2000. 794-813.

Revista Iberoamericana, Vol. LXXXI, Núm. 253, Octubre-Diciembre 2015, 1077-1094 